\title{
Flourishing as a dialectical balance: emerging insights from second-wave positive psychology
}

Tim Lomas ${ }^{1}$

\begin{abstract}
Positive psychology, an emergent branch of scholarship concerned with wellbeing and flourishing, initially defined itself by a focus on "positive" emotions and qualities. However, critics soon pointed out that this binary logic-classifying phenomena as either positive or negative, and valorising the former while disparaging the latter-could be problematic. For example, apparently positive qualities can be harmful to wellbeing in certain circumstances, while ostensibly dysphoric emotional states may on occasion promote flourishing. Responding to these criticisms, over recent years a more nuanced "second wave" of positive psychology has been developing, in which wellbeing is recognized as involving a dialectical balance of light and dark aspects of life. This article introduces this emergent second wave, arguing that it is characterized by four dialectical principles. First, the principle of appraisal states that it is difficult to categorically identify phenomena as either positive or negative, since such appraisals are fundamentally contextually dependent. Second, the principle of co-valence holds that many states and qualities at the heart of flourishing, such as love, are actually a complex blend of light and dark elements. Third, the principle of complementarity posits that not only are such phenomena co-valenced, but that their dichotomous elements are in fact co-creating, two intertwined sides of the same coin. Finally, the principle of evolution allows us to understand second-wave positive psychology as itself being an example of a dialectical process. This article is published as part of a collection entitled "On balance: lifestyle, mental health and wellbeing".
\end{abstract}

\footnotetext{
${ }^{1}$ Department of Psychology, University of East London, London, UK Correspondence: (e-mail: t.lomas@uel.ac.uk)
} 


\section{The evolution of positive psychology}

ust before the dawn of the new millennium, Martin Seligman used his ascension to the presidency of the American Psychological Association to inaugurate a bold new initiative: positive psychology (Seligman and Csikszentmihalyi, 2000). The rationale for its creation was Seligman's perceptive-if not universally endorsed-contention that mainstream psychology had hitherto tended to mainly concern itself with disorder and dysfunction. Certain fields had resisted this trend of course, focusing instead on human potential and excellence, such as humanistic psychology (Waterman, 2013). Nevertheless, on the whole, Seligman argued that concepts like happiness and flourishing were largely absent in mainstream psychology, removed from serious consideration, and regarded disparagingly by gatekeepers such as grant-awarding bodies. And so, Seligman used his influence and prominence to propose the notion of positive psychology as a way of redressing this lacuna. It swiftly became a fertile new paradigm, offering a "collective identity" for researchers interested in "the brighter sides of human nature" as Linley and Joseph (2004: 4) put it. As the field grew, it began to encompass research-much of which pre-dated the field itselfaround diverse processes and qualities that could be deemed "positive", from overarching constructs such as flourishing, to more specific concepts like optimism and hope.

As intimated above, it was not the case that this research was necessarily new. Before positive psychology strode boldly onto the scene, many of these topics had already been studied empirically by scholars in disparate fields, from humanistic to clinical psychology. Moreover, its central concerns-the nature of wellbeing and the good life-had been debated by scholars for centuries, millennia even (McMahon, 2006). However, part of the attraction and power of the new field was that it created a conceptual space where these diverse topics-all of which shared the "family resemblance" (Wittgenstein, 1953) of pertaining in some way to wellbeing-could be brought together and considered collectively. Thus, as a new field of enquiry focused specifically on "the science and practice of improving wellbeing" (Lomas et al., 2015: 1347), positive psychology found an enthusiastic response among students and scholars within psychology, and indeed in other fields, from education to social work (Lomas, 2015b).

However, the field was not without its critics. Some argued that its conceptualizations of wellbeing were culturally specificinfluenced by the North American context in which the field emerged-and yet the field tended to presume that these concepts were universally and perennially applicable (Becker and Marecek, 2008; Lomas, 2015a). Others accused the field of promulgating a "separatist" agenda, positioning itself as radically different to previous scholarship, and failing to recognize or engage with pertinent research in other fields (Cowen and Kilmer, 2002; Held, 2004). Another line of criticism was that the field tended towards the promotion of an individuation of social problems, and as such that it was aligned with a neo-liberal political agenda (McDonald and O'Callaghan, 2008). However, while there may be some merit to these claims, at least initially, it is also important to note that the field is responding receptively to these critiques. Objections around cultural bias are being addressed through the emergence of subfields like "positive cross-cultural psychology" (Lomas, 2015a), featuring analyses of phenomena such as linguistic differences in well-being related concepts (Lomas, 2016b). Critiques around the separatism of the field have led to attempts to build bridges with other fields, from "positive education" (Seligman et al., 2009) to "positive art" (Lomas, 2016a), which recognize the extensive work pertaining to wellbeing that has already happened within disciplines such as educational psychology and art therapy. Finally, the issue of individuation of social problems has given rise to more critical perspectives within the field, as highlighted by a forthcoming Handbook of Critical Positive Psychology (Brown et al., 2016), and the emergence of new sub-disciplines such as "positive social psychology" (Lomas, 2015b).

One of the most insightful and interesting critiques concerned the very notion of "positive" which underpinned the entire field, as articulated in particular by scholars such as Held (2002; 2004). The accusation was that positive psychology was promulgating a rather polarizing positive-negative dichotomy. Certain phenomena, emotions for example, were being labeled as positive, presented as inherently desirable and thus to be cultivated. The necessary corollary, of course, is that contrasting phenomena were implicitly conceptualized as negative, positioned as intrinsically undesirable and to be avoided. For example, optimism often appeared to be valorized as an unqualified good, and pessimism as intrinsically deleterious. It is true that some scholars did paint a more nuanced picture; for instance, Seligman (1990: 292) himself cautioned that one must be wary of being a "slave to the tyrannies of optimism", and that one needs to be "able to use pessimism's keen sense of reality when we need it". However, in terms of the broader discourse of the field, and its wider cultural impact, a less nuanced binary message-the simplistic valorization of ostensibly positive phenomenaappeared to be dominant.

Although this valorization of positivity seemed to offer an upbeat message-that positive emotions are linked to beneficial outcomes in multiple arenas, from health (Fredrickson and Levenson, 1998) to success (Boehm and Lyubomirsky, 2008)critics saw it as problematic. First, it often failed to appreciate sufficiently the context and complexity of emotional outcomes. For instance, "excessive" optimism can be harmful to wellbeing, particularly when it contributes to an under appreciation of risk and to subsequent health-risk behaviors such as smoking (Weinstein et al., 2005). Conversely, pessimism and anxiety may engender forms of proactive coping that are beneficial to wellbeing (Norem, 2001). Of even greater concern was Held's (2002: 965) contention that this emphasis on positivity contributed to a "tyranny of the positive" - that is, to a cultural expectation that one should be upbeat-which had deleterious consequences. For instance, Held argued that it fed into a climate in which people who could not find or express the requisite positivity might face social censure and even ostracism. Similarly, in her polemic against positivity, sociologist Ehrenreich (2009) accused companies of compelling positive thinking as a way of hindering dissent, and a means of cajoling more out of workers. Perhaps most perniciously, this "tyranny" added to a larger cultural discourse in which negative emotional states are not simply seen as undesirable, but as disorders. This discourse is part of a broader medicalization of existence, reflecting the cultural hegemony of medical fields such as psychiatry. As Horwitz and Wakefield (2007) suggest in The Loss of Sadness, emotions that were previously regarded as natural and inherent aspects of the human condition, from sadness to grief, have largely been re-framed as disorders, and certainly as problematic. And, it could be argued that positive psychology contributed, albeit perhaps unwittingly, to this process.

\section{Second-wave positive psychology}

If the very notion of "positive" is problematic, where does this leave positive psychology? Perhaps for some of the critics mentioned above, these criticisms might definitively undermine the field. However, an alternative perspective would be that such critiques in fact facilitate a more nuanced appreciation of the dynamics of flourishing. This is the view taken by myself and my colleagues. Challenged and provoked by these critiques, we feel that the field is responding receptively, evolving into what we call "secondwave" positive psychology (SWPP) (Wong, 2011; Lomas and 
Ivtzan, 2015; Ivtzan et al., 2015). If the "first wave" incarnation of the field can be defined by valorization of the positive, SWPP recognizes that flourishing instead involves a complex balance, a subtle, dialectical interplay between ostensibly positive and negative phenomena. Or rather, while this recognition may have been implicit in the first wave of the field, SWPP involves making it explicit. This second wave is still very much positive psychology: its overarching concern remains with "positive" meta-constructs and goals such as flourishing and wellbeing. It simply acknowledges that the routes towards these luminous destinations can be complicated, and sometimes lead through "darker" realms of human experience. More specifically, SWPP is underpinned by four dialectical principles: appraisal; co-valence; complementarity; and evolution.

The principle of appraisal cautions against categorically identifying phenomena as either positive or negative, since such appraisals are fundamentally contextually dependent. This was alluded to above, where it was noted that "excessive" optimism can lead to miscalculations of risk, whereas pessimism can be advantageous if it leads to prudence. One could problematize most emotional dichotomies in this way. For instance, McNulty and Fincham (2011) show that prosocial emotions like forgiveness can be problematic if it means one tolerates a situation that one might otherwise resist, such as a harmful relationship. Conversely, "anti-social" states like anger may be "moral emotions", which can alert us to ethical breaches, and motivate us to resist iniquities (Tavris, 1989). Indeed, "righteous" anger has been identified as a crucial driver of progressive change, inspiring and propelling social movements that have changed the world for the better, from Civil Rights to feminism (Siegel, 2009). Likewise, consider the polarity of freedom versus restraint. While the total deprivation of freedom, as in slavery, is surely an unqualified evil, existentialist thinkers have argued that an excess of freedom, a life untrammelled by restrictions, can be troubling (Yalom, 1980). For instance, Kierkegaard (1834) felt that this "dizzying" sense of unlimited possibilities could engender ontological "dread", since we must continually make choices that irrevocably shape our lives, and assume responsibility for the consequences. As Sartre (1952: 399) put it, people are "condemned to be free". In a more mundane but no less revealing way, Schwartz (2000: 79) reports that "excessive" consumer freedom can be experienced "as a kind of tyranny", with empirical studies suggesting that a greater diversity of choice often leads to lower levels of subsequent satisfaction (Iyengar and Lepper, 1999).

Even happiness and sadness are not immune from such considerations around the principle of appraisal. There is a risk, for example, that superficial forms of happiness, such as hedonistic pleasure, might forestall efforts to pursue deeper states of wellbeing that might ultimately prove more fulfilling (Wong, 2009). Or such pleasures might tranquilize us into acquiescing to social contexts that ultimately undermine our wellbeing, beguiling us by modest satisfactions into entering what Marxist theorists call "false consciousness," that is, a state of mind that prevents us from acting in our own interests (Jost, 1995). Thus, for instance, there is the accusation that consumer capitalism provides "the 99\%" with just enough recompense to prevent people from revolting en masse against a socio-economic system that systemically serves to fundamentally limit their wellbeing (DeLuca et al., 2012). Conversely, at times, sadness may be thoroughly appropriate, such as in response to loss, where grief is not only normal, but may actually maintain and honour one's connection to a departed loved one (Thieleman and Cacciatore, 2014). Similarly, sadness may be valuable as a humane reaction to suffering (Christiansen et al., 2010), or a refined aesthetic response to the ephemeral beauty of the world (Thoolen et al., 2009). Dwelling on such paradoxes, clear-cut determinations of "positive" and "negative" become harder to make.

Moreover, it is not just that such appraisals are difficult. The second principle of co-valence reflects the idea that many phenomena are complex admixtures of light and dark, positive and negative. Consider perhaps the way that hope involves a yearning optimism for a future goal, which is yet undercut with a gnawing anxiety that it may not come to pass (Lazarus, 2003). Such co-valence is perhaps most powerfully revealed in arguably the most cherished and exalted of all human phenomena: love. While there are many different forms of love-from the passion of eros to the selflessness of agape (Lee, 1977) - all can perhaps be understood as being a dialectical blend of light and dark. One might approach this dialectic in various ways, but all are essentially reflected in the poignant lamentation of C. S. Lewis (1971) that, "To love at all is to be vulnerable. Love anything and your heart will be wrung and possibly broken". Love can be troubled by the vicissitudes of fate in all kinds of ways, from enforced partings to an erosion of feelings over time. Thus, even while love contains pleasure, joy and bliss, it is also infused with worry, anxiety and fear. It is, as such, co-valenced, harbouring darker shades of feeling. This recognition leads us inexorably to the third principle: complementarity. Here we recognize that the potential dysphoria and vulnerability inherent in love are not aberrations, but the very condition of it. The light and dark of love are fundamentally inseparable, complementary and cocreating sides of the same coin. Consider that the stronger and more intense one's love for another, the greater the risk of heartbreak were the relationship to end against one's will. As Bauman (2013: 6) eloquently puts it, "to love means opening up to that most sublime of all human conditions, one in which fear blends with joy into an alloy that no longer allows its ingredients to separate".

With this third principle, we are in dialectical territory that has been explored with particular depth and insight by Eastern philosophies, especially Taoism. Taoism has its roots in the $I$ Ching, or "Book of Changes", which began life over 3000 years ago as a shamanic practice among the Chou people, based on the practice of consulting oracles (Wilhelm, 1950). The overarching philosophical principle of the I Ching is change, which, paradoxically, is the one eternal, immutable law at work in the universe. Moreover, the I Ching identified the mechanism through which change occurs: the dialectical interaction between opposites (Fang, 2012). This dialectical interaction was subsequently captured symbolically by the yin-yang motif (although the terms themselves do not appear in the book; instead we find dichotomies such as "the firm" and "the yielding"). Yin means cloudy/overcast, whereas Yang means "in the sun" (that is, shone upon), implying the two sides of a mountain (one sunlit, one in shadow). Thus, as Fang (2012) explains, yin-yang encapsulates various "tenets of duality". The tenet of "holistic duality" means that reality comprises co-dependent opposites that each require the other for their existence (for, "up" depends upon the notion of "down"). Moreover, the tenet of "dynamic duality" holds that these opposites tend to mutually transform into each other in a dynamic process; as Fung (1948: 19) puts it, "When the sun has reached its meridian, it declines" (that is, its zenith heralds the beginning of the descent into night). Thus, yin-yang does not simply present a pair of static opposites, but includes an element of darkness in the light, and vice versa, capturing the ceaseless process of becoming. As Ji et al. (2001: 450) put it, "The pure yin is hidden in yang, and the pure yang is hidden in yin". Such considerations beautifully encapsulate the principle of complementarity, which can arguably be applied to all emotional dichotomies that combine to constitute flourishing, from optimism versus pessimism to freedom versus restriction. 
Finally, the principle of evolution allows us to contextualize the very idea of SWPP. Just as SWPP is defined by an appreciation of dialectics, it is itself an example of a dialectical process. Here I refer to the dialectical movement of thesis-antithesis-synthesis associated with G.W.F. Hegel (1770-1831). One might view mainstream psychology, with its apparent concern with "negative" aspects of human functioning, as the thesis. In critiquing this and embracing ostensibly positive phenomena, positive psychology presented itself as the antithesis. However, critics subsequently began to discern flaws in this antithesis, as elucidated above, pointing out the pitfalls of positive qualities and the potential merits of negative ones. Crucially though, from a Hegelian perspective, this does not necessarily mean an abandonment of positive psychology, a reversion back to the original thesis. Rather, the next stage in this dialectical process is ideally synthesis, in which the truths of both thesis and antithesis are preserved, while the flaws in their respective positions are overcome. And, one might argue, SWPP is just such a synthesis: there is a movement away from a binary classification of phenomena as either positive and negative-valorizing the former while condemning the latter-towards a more nuanced appreciation of the dialectical complexities of flourishing.

\section{Conclusion}

This article has provided a summary of SWPP, which is characterized above all by appreciation of the dialectical nature of wellbeing (supported by subsidiary elements, such as a critical attention to context). It was suggested that this dialectical appreciation centres on three key components: the principle of appraisal (the difficulty of categorising phenomena as either positive or negative), the principle of co-valence (the notion that many experiences involve a blend of positive and negative elements), and the principle of complementarity (the idea that wellbeing and flourishing depend upon a complex balance of light and dark aspects of life). In addition, SWPP itself was seen as the manifestation of a fourth dialectical principle, namely evolution, in that it is a synthesis, emerging from the interaction of "psychology as usual" (the thesis) and positive psychology (the antithesis). These considerations show the way in which positive psychology is evolving as a discipline, and point the way ahead to future scholarship on the nature of wellbeing.

\section{References}

Bauman Z (2013) Liquid Love: On the Frailty of Human Bonds. John Wiley \& Sons: New York.

Becker D and Marecek J (2008) Dreaming the American dream: Individualism and positive psychology. Social and Personality Psychology Compass; 2 (5): 1767-1780.

Boehm JK and Lyubomirsky S (2008) Does happiness promote career success? Journal of Career Assessment; 16 (1): 101-116.

Brown NJL, Lomas T and Eiroa-Orosa F (eds.) (2016) The Routledge International Handbook of Critical Positive Psychology. Routledge: London.

Christiansen S, Oettingen G, Dahme B and Klinger R (2010) A short goal-pursuit intervention to improve physical capacity: A randomized clinical trial in chronic back pain patients. PAIN; 149 (3): 444-452.

Cowen EL and Kilmer RP (2002) "Positive psychology": Some plusses and some open issues. Journal of Community Psychology; 30 (4): 449-460.

DeLuca KM, Lawson S and Sun Y (2012) Occupy wall street on the public screens of social media: The many framings of the birth of a protest movement. Communication, Culture \& Critique; 5 (4): 483-509.

Ehrenreich B (2009) Smile or Die: How Positive Thinking Fooled America and the World. Granta: London.

Fang T (2012) Yin Yang: A new perspective on culture. Management and Organization Review; 8 (1): 25-50.

Fredrickson B and Levenson RW (1998) Positive emotions speed recovery from the cardiovascular sequelae of negative emotions. Cognition and Emotion; 12 (2): 191-220.

Fung L-Y (1948) A Short History of Chinese Philosophy. The Free Press: New York.
Held BS (2002) The tyranny of the positive attitude in America: Observation and speculation. Journal of Clinical Psychology; 58 (9): 965-991.

Held BS (2004) The negative side of positive psychology. Journal of Humanistic Psychology; 44 (1): 9-46.

Horwitz AV and Wakefield JC (2007) The Loss of Sadness. Oxford University Press: Oxford.

Ivtzan I, Lomas T, Hefferon K and Worth P (2015) Second Wave Positive Psychology: Embracing the Dark Side of Life. Routledge: London.

Iyengar SS and Lepper MR (1999) Rethinking the value of choice: A cultural perspective on intrinsic motivation. Journal of Personality and Social Psychology; 76 (3): 349-366.

Ji LJ, Nisbett RE and Su Y (2001) Culture, change, and prediction. Psychological Science; 12 (6): 450-456.

Jost JT (1995) Negative illusions: Conceptual clarification and psychological evidence concerning false consciousness. Political Psychology; 16 (2): 397-424.

Kierkegaard S (1834/1957) The Concept of Dread; Translated by W. Lowrie. 2nd edn., Princeton University Press: Princeton, NJ.

Lazarus RS (2003) The Lazarus manifesto for positive psychology and psychology in general. Psychological Inquiry; 14 (2): 173-189.

Lee JA (1977) A typology of styles of loving. Personality and Social Psychology Bulletin; 3 (2): 173-182.

Lewis CS (1971) The Four Loves. Houghton Mifflin Harcourt: New York.

Linley PA and Joseph S (eds) (2004) Applied positive psychology: A new perspective for professional practice In: Positive Psychology in Practice. John Wiley and Sons: Hoboken, NJ, pp 3-12.

Lomas T (2015a) Positive cross-cultural psychology: Exploring similarity and difference in constructions and experiences of wellbeing. International Journal of Wellbeing; 5 (4): 60-77.

Lomas T (2015b) Positive social psychology: A multilevel inquiry into sociocultural wellbeing initiatives. Psychology, Public Policy, and Law; 21 (3): $338-347$.

Lomas T (2016a) Positive art: Artistic expression and appreciation as an exemplary vehicle for flourishing. Review of General Psychology; doi: 10.1037/gpr0000073.

Lomas T (2016b) Towards a positive cross-cultural lexicography: Enriching our emotional landscape through 216 "untranslatable" words pertaining to wellbeing. The Journal of Positive Psychology; doi:10.1080/17439760.2015. 1127993.

Lomas T, Hefferon K and Ivtzan I (2015) The LIFE model: A meta-theoretical conceptual map for applied positive psychology. Journal of Happiness Studies; 16 (5): $1347-1364$.

Lomas $\mathrm{T}$ and Ivtzan I (2015) Second wave positive psychology: Exploring the positive-negative dialectics of wellbeing. Journal of Happiness Studies; doi:10.1007/s10902-015-9668-y.

McDonald M and O'Callaghan J (2008) Positive psychology: A Foucauldian critique. Journal of Humanistic Psychology; 36 (2): 127-142.

McMahon DM (2006) Happiness: A History. Atlantic Monthly Press: New York.

McNulty JK and Fincham FD (2011) Beyond positive psychology? Toward a contextual view of psychological processes and well-being. American Psychologist; 67 (2): 101-110.

Norem JK (2001) The Positive Power of Negative Thinking. Basic Books: New York. Sartre J-P (1952) Existentialism and Humanism; Translated by P. Mairet. Methuen: Paris, France.

Schwartz B (2000) Self-determination: The tyranny of freedom. American Psychologist; 55 (1): 79-88.

Seligman MEP (1990) Learned Optimism. Pocket Books: New York.

Seligman MEP and Csikszentmihalyi M (2000) Positive psychology: An introduction. American Psychologist; 55 (1): 5-14.

Seligman MEP, Ernst RM, Gillham J, Reivich K and Linkins M (2009) Positive education: Positive psychology and classroom interventions. Oxford Review of Education; 35 (3): 293-311.

Siegel A (2009) Justice Stevens and the seattle schools case: A case study on the role of righteous anger in constitutional discourse. UC Davis Law Review; 43, 927-937.

Tavris C (1989) Anger: The Misunderstood Emotion. Touchstone: New York.

Thieleman K and Cacciatore J (2014) When a child dies: A critical analysis of griefrelated controversies in DSM-5. Research on Social Work Practice; 24 (1): 114-122.

Thoolen BJ, Ridder DD, Bensing J, Gorter K and Rutten G (2009) Beyond good intentions: The role of proactive coping in achieving sustained behavioural change in the context of diabetes management. Psychology and Health; 24 (3): 237-254.

Waterman AS (2013) The humanistic psychology-positive psychology divide: Contrasts in philosophical foundations. American Psychologist; 68 (3): 124-133.

Weinstein ND, Marcus SE and Moser RP (2005) Smokers' unrealistic optimism about their risk. Tobacco Control; 14 (1): 55-59.

Wilhelm H (1950/1977) The I Ching or Book of Changes; Translated by C.F. Baynes. Princeton University Press: New York. 
Wittgenstein L (1953) Philosophical Investigations. Palgrave Macmillan: New York. Wong PTP (2009) Positive existential psychology In: Lopez SJ (ed) Encyclopedia of Positive Psychology; Blackwell: Oxford, pp 345-351.

Wong PTP (2011) Positive psychology 2.0: Towards a balanced interactive model of the good life. Canadian Psychology/Psychologie canadienne; 52 (2): 69-81.

Yalom I (1980) Existential Therapy. Basic Books: New York.

\section{Additional Information}

Competing interests: The authors declare no competing financial interests.

Reprints and permission information is available at http://www.palgrave-journals.com/ pal/authors/rights_and_permissions.html
How to cite this article: Lomas T (2016) Flourishing as a dialectical balance: emerging insights from second-wave positive psychology. Palgrave Communications. 2:16018 doi: $10.1057 /$ palcomms.2016.18.

(c) (i) This work is licensed under a Creative Commons Attribution 4.0 International License. The images or other third party material in this article are included in the article's Creative Commons license, unless indicated otherwise in the credit line; if the material is not included under the Creative Commons license, users will need to obtain permission from the license holder to reproduce the material. To view a copy of this license, visit http://creativecommons.org/licenses/by/4.0/ 